impressed by the rather small amount of space between the cells in the marginal zone, so the cross-section available for diffusion must be very small indeed. It seems very unlikely that a protein such as activin could actually pass through the cells, so one wonders whether the cell surface or extracellular matrix embodies some special transport mechanism. If it does, then it is presumably shared by the non-responding cells used in Gurdon's experiments.

Third, there is the question of the sharpness of the responses. Although experiments involving cell reaggregation have shown sharp threshold responses ${ }^{7}$, it is now known that the initial activation of $X b r a$ following activin treatment follows a smooth dose-response ${ }^{8,9}$ and after a few hours the boundary sharpens, both in vivo and in the present experiments. One way of creating a sharp threshold is by a bistable circuit in which there is a positive feedback that can amplify the level of a substance once it is raised above the critical threshold ${ }^{10}$, and it has recently been shown ${ }^{11}$ that there is a potential bistable loop in the early Xenopus embryo made up of the genes encoding the $\mathrm{Xbra}$ product and embryonic fibroblast growth factor. The operation of this circuit may perhaps be the mechanism that sharpens the initially smooth response.

In their paper, Gurdon et al. are at some pains to argue for the importance of activin itself in early Xenopus development. This is perhaps exaggerated, because there is very little activin protein in the egg and levels of new activin transcription remain very low before the neurula stage $\mathrm{s}^{12,13}$. Furthermore, inhibition of endogenous activin by over- expression of follistatin produces essentially no phenotype ${ }^{14}$.

In my view, the significance of the present work is not so much that it tells us specifically about Xenopus development, but that it uses the versatile Xenopus embryo to create a system which can be used to study the general spatial properties of cellular signalling and response. This could be relevant not just to the problems of embryonic development, interesting though they are, but also to comparable situations in the adult organism such as tissue regeneration, the organization of epithelial proliferative units, or the interactions within the stem cell 'niches' of the bone marrow.

J. M. W. Slack is in the ICRF Developmental Biology Unit, Department of Zoology, University of Oxford, Oxford OX1 3PS, UK. OBITUARY

\title{
Karl Popper (1902-1994)
}

WITH the death of Sir Karl Popper on 17 September, the scientific community has lost the philosopher who many of us feel illuminated, far more than any other, the way in which we work. His notions could be used with great advantage to evaluate whether a particular piece of research should or should not be regarded as scientific. Although many scientists have little interest in the philosophy of science, and some of those with such an interest are not too keen on Popper's teaching, to me his thoughts came as a flash of brilliant light. In this attitude I was proud to join Peter Medawar, Popper's most influential follower in the British scientific world.

Popper lived in the Vienna of the Positivists until his midthirties, then lectured in New Zealand. In 1945 the London School of Economics, to its lasting credit, brought him to Eng. land, where he remained. His seminal work in the philosophy of science, published in German in 1934 as Die Logik der Forschung, became available in English only in 1959 , but its principal ideas were already well appreciated in the English-speaking countries by that time. The most immediate one is that science is demarcated from other endeavours (or should one say 'defined'?) by the primacy of empirical disproof: only theories which can, at least in principle, be found to be wrong by experiment or observation are entitled to be called scientific.

This criterion is of great value in many fields of science. But Popper's contributions to the philosophy of science go far

beyond this hypothetico-deductive outlook. He was very clear that determinism makes little, if any, sense. Indeterminacy is to be welcomed, not regretted. If earlier philosophers had had Popper's insight it might have become clear long ago that Dalton's 'identical' constituents

\section{IMAGE UNAVAILABLE FOR COPYRIGHT REASONS}

Popper - a remarkable and most memorable personality.

of matter necessitated a new kind of statistics, and similarly the thought that a maximum velocity for signalling put uni. versal simultaneity in question might not have had to wait for Einstein. Popper's attitude to the Copenhagen interpretation of quantum theory has struck less of an echo, and he took some time to come to a positive view of the status of the theory of evolution.

His demolition of the scientific preten- sions of psychoanalysis and of Marxism was brilliant and effective. Indeed Popper's political philosophy, especially as displayed in his The Open Society and its Enemies, is most impressive for its prag. matism and humanity. It is a powerful call for democracy and a severe indictment of those who are so sure of their prescriptions that they are prepared to slaughter millions in their pursuit. A most accessible introduction to his thoughts is to be found in Bryan Magee's little paperback Popper (Fontana, 1973).

I must also speak of Karl Popper as a person. I had the pleasure of knowing him, and I parti. cularly recall visits to his home in Penn when his kind, self-effacing wife Hennie was still alive. The atmosphere in that quiet house was so purely intellectual that nothing else seemed to exist. It was reminiscent of Hermann Hesse's Glass Bead Game. In. deed he often gave the impress. ion of living in a world of his own, an impression reinforced by his deafness and his extreme objection to tobacco. Nonetheless, honours were showered on this retiring little man in his later life - I like to think that he particularly enjoyed the recognition by the scientific establishment when he became a Fellow of the Royal Society in 1976.

$A$ remarkable and most memorable personality is gone, but a life wholly filled with intellectual labours is made permanent by his many books. Hermann Bondi

Hermann Bondi is at Churchill College, Cambridge CB3 ODS, UK. 